\title{
Efficacy and safety of CHF6001, a novel inhaled PDE4 inhibitor in COPD: the PIONEER study
}

Dave Singh $^{1 *}$ (D, Aida Emirova ${ }^{2}$, Catherine Francisco ${ }^{2}$, Debora Santoro ${ }^{2}$, Mirco Govoni ${ }^{2}$ and Marie Anna Nandeuil ${ }^{2}$

\begin{abstract}
Background: This study evaluated the efficacy, safety and tolerability of the novel inhaled phosphodiesterase-4 inhibitor CHF6001 added-on to formoterol in patients with chronic obstructive pulmonary disease (COPD).

Methods: Randomised, double-blind, placebo- and active-controlled, parallel-group study. Eligible patients had symptomatic COPD, post-bronchodilator forced expiratory volume in $1 \mathrm{~s}\left(\mathrm{FEV}_{1}\right) 30-70 \%$ predicted, and history of $\geq 1$ moderate/severe exacerbation. Patients were randomised to extrafine CHF6001 400, 800, 1200 or $1600 \mu \mathrm{g}$ twice daily (BID), budesonide, or placebo for 24 weeks. Primary objectives: To investigate CHF6001 dose-response for predose $\mathrm{FEV}_{1}$ after 12 weeks, and to identify the optimal dose. Moderate-to-severe exacerbations were a secondary endpoint.
\end{abstract}

Results: Of 1130 patients randomised, 91.9\% completed. Changes from baseline in pre-dose FEV ${ }_{1}$ at Week 12 were small in all groups (including budesonide), with no CHF6001 dose-response, and no significant treatment-placebo differences. For moderate-to-severe exacerbations, CHF6001 rate reductions versus placebo were 13-28\% (nonsignificant). In post-hoc analyses, CHF6001 effects were larger in patients with a chronic bronchitis phenotype (rate reductions versus placebo 24-37\%; non-significant), and were further increased in patients with chronic bronchitis and eosinophil count $\geq 150$ cells/ $\mu \mathrm{L}$ (49-73\%, statistically significant for CHF6001 800 and $1600 \mu \mathrm{g}$ BID). CHF6001 was well tolerated with no safety signal (including in terms of gastrointestinal adverse events).

Conclusions: CHF6001 had no effect in the primary lung function analysis, although was well-tolerated with no gastrointestinal adverse event signal. Post-hoc analyses focused on exacerbation risk indicate specific patient subgroups who may receive particular benefit from CHF6001.

Trial registration: ClinicalTrials.gov (NCT02986321). Registered 8 Dec 2016.

Keywords: Acute exacerbations of COPD, Chronic obstructive pulmonary disease, Chronic bronchitis, Phosphodiesterase inhibitors

\footnotetext{
*Correspondence: dsingh@meu.org.uk

${ }^{1}$ Medicines Evaluation Unit, The University of Manchester, Manchester University NHS Foundation Trust, Manchester, UK

Full list of author information is available at the end of the article
}

(c) The Author(s). 2020 Open Access This article is licensed under a Creative Commons Attribution 4.0 International License, which permits use, sharing, adaptation, distribution and reproduction in any medium or format, as long as you give appropriate credit to the original author(s) and the source, provide a link to the Creative Commons licence, and indicate if changes were made. The images or other third party material in this article are included in the article's Creative Commons licence, unless indicated otherwise in a credit line to the material. If material is not included in the article's Creative Commons licence and your intended use is not permitted by statutory regulation or exceeds the permitted use, you will need to obtain permission directly from the copyright holder. To view a copy of this licence, visit http://creativecommons.org/licenses/by/4.0/. The Creative Commons Public Domain Dedication waiver (http://creativecommons.org/publicdomain/zero/1.0/) applies to the data made available in this article, unless otherwise stated in a credit line to the data. 


\section{Background}

Phosphodiesterase-4 (PDE4) inhibition has an established role in the management of chronic obstructive pulmonary disease (COPD); roflumilast is an antiinflammatory drug that prevents exacerbations in the subgroup of patients with a chronic bronchitis phenotype [1]. Roflumilast is taken orally and consequently is associated with a higher incidence of systemic adverse events related to PDE4 inhibition including diarrhoea, nausea, weight loss and abdominal pain, resulting in both substantial treatment discontinuation in clinical practice and withdrawal from clinical trials [1-7].

CHF6001 is a novel inhaled PDE4 inhibitor [8,9] that has been developed as an extrafine formulation (i.e., with mass median aerodynamic diameter $\leq 2 \mu \mathrm{m}$ ) and to have low systemic exposure. This allows CHF6001 to reach a therapeutic concentration in the target organ, the lung, with reduced systemic exposure, limiting systemic adverse effects. Indeed, CHF6001 inhaled twice daily (BID) has previously demonstrated lung-targeted antiinflammatory effects in patients with COPD and a chronic bronchitis phenotype $[10,11]$.

The aim of this study was to evaluate the efficacy, safety and tolerability of CHF6001 in patients with COPD when added on to a bronchodilator (formoterol fumarate), and to identify the optimal dose(s) of CHF6001 for further development. In addition to reporting the pre-specified results of the study, this manuscript presents the results from a series of post-hoc analyses that explored the effect of CHF6001 (in terms of moderate-to-severe exacerbations) in various patient subgroups.

\section{Methods}

\section{Trial design and participants}

This was a multicentre, randomised, double-blind, double-dummy, placebo- and active-controlled, parallelgroup, dose-ranging study. Eligible patients were at least 40 years of age, with a diagnosis of COPD, a smoking history of at least 10 pack-years (current and ex-smokers were eligible), post-bronchodilator forced expiratory volume in $1 \mathrm{~s}\left(\mathrm{FEV}_{1}\right) 30-70 \%$ predicted, a history of at least one moderate or severe exacerbation in the previous 12 months, symptomatic (modified Medical Research Council dyspnoea score $\geq 2$ and COPD Assessment Test score $\geq 10$ ), and receiving daily maintenance therapy with an inhaled corticosteroid (ICS) and a longacting $\beta_{2}$-agonist (LABA) at a stable dose and regimen for at least 2 months prior to entry. Key exclusion criteria were: a diagnosis of asthma or other respiratory disease that might impact data interpretation; and a moderate or severe exacerbation in the 8 weeks prior to study entry. All patients provided written informed consent prior to any study-related procedure. Full inclusion and exclusion criteria are listed in Additional file 1.

Patients who met the inclusion and exclusion criteria entered a two-week run-in period during which they received formoterol fumarate $12 \mu \mathrm{g}$ BID plus salbutamol as required. At the baseline visit, patients were randomised equally to one of six treatment groups: one of four extrafine CHF6001 doses (400, 800, 1200 or $1600 \mu \mathrm{g}$ BID) via dry powder inhaler (DPI), budesonide $400 \mu \mathrm{g}$ BID via a different DPI, or placebo. All patients continued to receive formoterol fumarate BID and salbutamol as required throughout the study. Patients were assigned to treatment centrally via interactive voice response technology, using a balanced block randomisation scheme stratified by site. Patients, investigators, and site and sponsor staff were blinded to treatment assignment by use of a double-dummy design, with matching placebo to CHF6001 DPI, and matching placebo to budesonide DPI.

Patients returned to the study site for visits after 3,6 , 12,18 and 24 weeks, when data were captured from predose spirometry (slow vital capacity manoeuvres for inspiratory capacity [IC] and forced vital capacity [FVC] manoeuvres for $\mathrm{FEV}_{1}$ and FVC), and from the Transition Dyspnea Index (TDI) and St George's Respiratory Questionnaire (SGRQ). Patients completed an electronic diary daily, in which they recorded symptoms (using the Exacerbations of Chronic Pulmonary Disease Tool - Respiratory Symptoms [E-RS]) and rescue medication use. The occurrence of exacerbations was captured throughout the study, with moderate exacerbations defined as those requiring treatment with systemic corticosteroids and/or antibiotics, and severe exacerbations requiring hospitalisation or resulting in death. Adverse events (AEs) were captured throughout the study, with safety evaluated using haematology, blood chemistry, urinalysis, vital signs and 12-lead electrocardiograms (ECG).

The study was approved by the independent ethics committees or research boards at each institution, and was performed in accordance with the principles of the Declaration of Helsinki, and the International Conference on Harmonisation notes for guidance on Good Clinical Practice (ICH/CPMP/135/95). There were no substantial protocol amendments that impacted recruited patients. Study registration: ClinicalTrials.gov (NCT02986321).

\section{Outcomes}

The primary objectives of the study were to investigate the dose-response relationship of CHF6001 with respect to pre-dose $\mathrm{FEV}_{1}$ after 12 weeks, and to identify the optimal dose of CHF6001. Secondary objectives were to compare CHF6001 with placebo and with budesonide over 24 weeks in terms of: pre-dose $\mathrm{FEV}_{1}, \mathrm{FVC}$ and IC, 
TDI focal score, SGRQ total score, E-RS total score, rescue medication use, and the rate of moderate-to-severe exacerbations. Safety and tolerability were also monitored as a secondary objective.

As exploratory objectives, the effects of CHF6001 versus placebo were evaluated on systemic C-reactive protein $(\mathrm{CRP})$, fibrinogen, surfactant protein $\mathrm{D}$ (SP-D), club cell protein 16 (CC-16), interleukin-6 (IL-6), IL-8 and blood eosinophil count, using the same methods as presented in Singh et al [10].

\section{Sample size and statistical methods}

The study was powered on the slope of line obtained by regressing pre-dose $\mathrm{FEV}_{1}$ change at Week 12 (the primary endpoint) against dose (i.e., linear dose-response) [12]. It was estimated that 735 evaluable patients (147 in each of the CHF6001 and placebo groups) would be sufficient to reject the null hypothesis that the slope equalled zero with an $80 \%$ power and a two-sided alpha level of significance of 0.05 , assuming a standard deviation of $240 \mathrm{~mL}$ and that a change of $70 \mathrm{~mL}$ would be reached with CHF6001 $1600 \mu \mathrm{g}$ BID. The same number of evaluable patients was included in the budesonide group. The power of the calculated sample size to fit a significant $\mathrm{E}_{\max }$ model was estimated across 1 thousand simulations to be $87.5 \%$. Given an estimated drop-out rate of $20 \%$, it was planned to randomise 1102 patients to obtain 882 evaluable patients.

The dose-response relationship of CHF6001 was explored using linear, $\mathrm{E}_{\max }$, and linear-log models. Change from baseline in pre-dose morning $\mathrm{FEV}_{1}$ was analysed using a linear mixed model for repeated measures (MMRM) including treatment, visit, treatment by visit interaction and sites pooled by country, as effects, and baseline $\mathrm{FEV}_{1}$ value and baseline by visit interaction as covariates. Most of the secondary efficacy endpoints were analysed using a similar MMRM to that used for the primary efficacy endpoint. Biomarker data (logtransformed values) were analysed using an analysis of covariance model including treatment and sites pooled by country as fixed effects, and the baseline value as covariate. The moderate-to-severe COPD exacerbation rate was analysed using a negative binomial model including treatment and sites pooled by country as factors, and logarithm of time into the study as an offset; the adjusted exacerbation rates in each group and the adjusted rate ratios versus placebo were estimated by the model. In addition, a series of hypothesis-generating post-hoc analyses were performed on the moderate-to-severe COPD exacerbation rate data using the same model in three subgroups: patients with a chronic bronchitis phenotype; using a blood eosinophil value threshold at baseline of 150 cells $/ \mu \mathrm{L}$; and patients with a combined chronic bronchitis phenotype and blood eosinophil level $\geq 150$ cells $/ \mu \mathrm{L}$ at baseline. All data were analysed using Statistical Analysis System software Version 9.4.

The intention-to-treat (ITT) population, defined as all randomised patients who received at least one dose of study medication and who had at least one available post-baseline efficacy evaluation, was used for all efficacy evaluations. Safety evaluations were performed on the safety set, which was all randomised patients who received at least one dose of study medication.

\section{Results \\ Participants}

The study was conducted between 15 December 2016 and 9 January 2018 in seven countries (Bulgaria, Germany, Hungary, Poland, Russia, Ukraine and United Kingdom). Of 1130 patients randomised, 1038 (91.9\%) completed the study, with the proportion of patients withdrawing (and the reasons for withdrawal) similar in each group (Fig. 1). Baseline demographics and disease characteristics were similar between groups (Table 1).

\section{Outcomes \\ Lung function}

For the primary endpoint (pre-dose $\mathrm{FEV}_{1}$ at Week 12), changes from baseline were small in all groups. There was no clear dose-response for CHF6001 in the linear, $\mathrm{E}_{\max }$, or linear-log models, with adjusted mean treatment-placebo differences of $2,17,10$, and $-18 \mathrm{~mL}$ for CHF6001 400, 800, 1200 and $1600 \mu \mathrm{g}$ BID, respectively, and $4 \mathrm{~mL}$ for budesonide, none of which were statistically significant. Results were similar at other visits, with changes from baseline small, and no significant differences between groups (Fig. 2). Similarly, for pre-dose FVC and IC, changes from baseline were small, and there were no consistent treatment-placebo or CHF6001-budesonide differences, and no CHF6001 dose-response effect (see Additional file 1: Supplementary Figures 1 and 2).

\section{Symptoms-related endpoints}

There were no consistent treatment-placebo or CHF6001-budesonide differences, with improvements from baseline in the symptoms-related endpoints TDI, SGRQ and E-RS at all timepoints in all groups, including placebo (Table 2, Additional file 1: Supplementary Figures 3-5). Similarly, there were no consistent treatment-placebo or CHF6001-budesonide differences in rescue medication use (see Additional file 1: Supplementary Figures 6 and 7).

\section{Exacerbations}

The adjusted annualised rates of moderate-to-severe exacerbations were $0.56,0.59,0.59$ and 0.49 for CHF6001 400, 800, 1200 and $1600 \mu \mathrm{g}$ BID, respectively, 0.42 for 


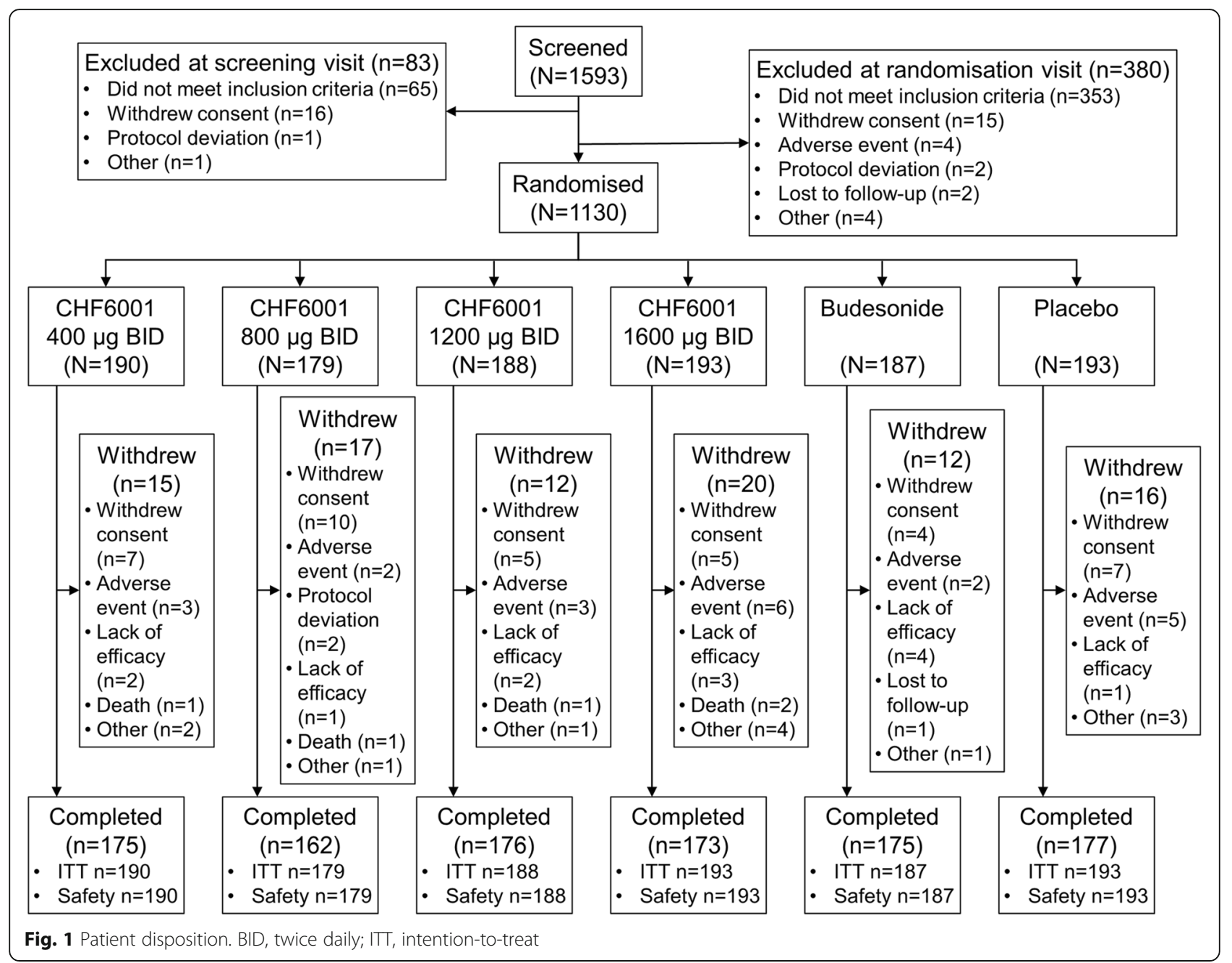

budesonide and 0.68 for placebo (Fig. 3a). Nonstatistically significant exacerbation rate reductions were observed with the four CHF6001 treatment groups compared with placebo, ranging from 13 to $28 \%$ (Fig. 3d). In the budesonide group there was a $39 \%$ reduction in the exacerbation rate compared to placebo $(p=0.030)$.

In the post-hoc analysis conducted only in patients with a chronic bronchitis phenotype, the effect of CHF6001 was numerically larger than in the overall analysis, but still statistically non-significant, with rate reductions versus placebo of $24-37 \%$ (Fig. 3a and d); the effect of budesonide in this subgroup was numerically similar to that in the overall population (38\% reduction versus placebo; non-significant). When analysed according to eosinophil count at baseline, the effect of the four CHF6001 doses was generally larger in patients with blood eosinophil counts $\geq 150$ cells $/ \mu \mathrm{L}$ than $<150$ cells/ $\mu \mathrm{L}$ (especially for $1600 \mu \mathrm{g}$ BID, where the rate reduction versus placebo was $51 \%$ in the $\geq 150$ cells $/ \mu \mathrm{L}$ group, $p=$ 0.010 ), as was that of budesonide (58\%, $p=0.006$; Fig. $3 \mathrm{~b}$ and d). Combining these two subgroups (i.e., patients with a chronic bronchitis phenotype and with eosinophil count $\geq 150$ cells $/ \mu \mathrm{L}$ ) further increased the treatment effect versus placebo, with rate reductions versus placebo of $49-73 \%$ with CHF6001 (reaching statistical significance for the 800 and $1600 \mu \mathrm{g}$ BID doses, $p=0.005$ and $p=0.019$, respectively) and $63 \%$ for budesonide $(p=$ 0.019; Fig. 3c and d).

\section{Biomarkers}

All four CHF6001 doses significantly reduced the levels of SP-D versus placebo (with no indication of doseresponse), whereas the levels were unchanged in the budesonide group (Fig. 4). None of the treatments had consistent effects on any of the other blood biomarkers with the exception of blood eosinophil levels, where budesonide significantly decreased counts versus placebo at both Week 12 and Week 24, whereas CHF6001 did not (see Additional file 1: Supplementary Table 1). 
Table 1 Baseline demographics and disease characteristics

\begin{tabular}{|c|c|c|c|c|c|c|c|}
\hline & \multicolumn{4}{|l|}{ CHF6001 } & \multirow{2}{*}{$\begin{array}{l}\text { Budesonide } \\
800 \mu \mathrm{g}(N= \\
187)\end{array}$} & \multirow{2}{*}{$\begin{array}{l}\text { Placebo } \\
(N=193)\end{array}$} & \multirow{2}{*}{$\begin{array}{l}\text { Overall } \\
(N=1130)\end{array}$} \\
\hline & $\begin{array}{l}400 \mu \mathrm{g} \text { BID } \\
(N=190)\end{array}$ & $\begin{array}{l}800 \mu \mathrm{g} B I D \\
(N=179)\end{array}$ & $\begin{array}{l}1200 \mu \mathrm{gBID} \\
(N=188)\end{array}$ & $\begin{array}{l}1600 \mu \mathrm{g} \mathrm{BID} \\
(N=193)\end{array}$ & & & \\
\hline Age (years) & $64.0(8.5)$ & $65.2(7.9)$ & $65.2(8.6)$ & $62.9(8.4)$ & $64.7(7.8)$ & $64.5(8.0)$ & $64.4(8.2)$ \\
\hline Sex, male & $133(70.0)$ & $129(72.1)$ & $131(69.7)$ & $135(69.9)$ & $132(70.6)$ & $133(68.9)$ & $793(70.2)$ \\
\hline \multicolumn{8}{|l|}{ Race } \\
\hline Asian & 0 & 0 & 0 & 0 & $1(0.5)$ & 0 & $1(0.1)$ \\
\hline White & $190(100)$ & $179(100)$ & $188(100)$ & $193(100)$ & $186(99.5)$ & $193(100)$ & $1129(99.9)$ \\
\hline $\mathrm{BMI}\left(\mathrm{kg} / \mathrm{m}^{2}\right)$ & $26.20(4.04)$ & $26.36(3.64)$ & $26.19(4.03)$ & $26.10(3.98)$ & $26.04(3.82)$ & $26.05(3.73)$ & $26.16(3.87)$ \\
\hline Time since COPD diagnosis (years) & $8.9(6.1)$ & $8.6(5.9)$ & $9.0(5.8)$ & $8.3(5.3)$ & $9.4(6.4)$ & $8.7(5.3)$ & $8.8(5.8)$ \\
\hline \multicolumn{8}{|l|}{ Main COPD phenotype ${ }^{a}$} \\
\hline Chronic bronchitis only & $101(53.2)$ & $93(52.0)$ & $107(56.9)$ & $113(58.5)$ & $106(56.7)$ & $108(56.0)$ & $628(55.6)$ \\
\hline Emphysema only & $39(20.5)$ & $41(22.9)$ & $34(18.1)$ & $36(18.7)$ & $36(19.3)$ & $42(21.8)$ & $228(20.2)$ \\
\hline Mixed & $50(26.3)$ & $45(25.1)$ & $47(25.0)$ & $44(22.8)$ & $45(24.1)$ & $43(22.3)$ & $274(24.2)$ \\
\hline Exacerbations in previous year & $1.2(0.4)$ & $1.1(0.4)$ & $1.1(0.3)$ & $1.1(0.4)$ & $1.1(0.4)$ & $1.1(0.4)$ & $1.1(0.4)$ \\
\hline 1 & $160(84.2)$ & $157(87.7)$ & $164(87.2)$ & $173(89.6)$ & $161(86.1)$ & $174(90.2)$ & $989(87.5)$ \\
\hline 2 & $30(15.8)$ & 19 (10.6) & $24(12.8)$ & $16(8.3)$ & $24(12.8)$ & $17(8.8)$ & $130(11.5)$ \\
\hline$>2$ & 0 & $3(1.7)$ & 0 & $4(2.1)$ & $2(1.1)$ & $2(1.0)$ & $11(1.0)$ \\
\hline \multicolumn{8}{|l|}{ Smoking history } \\
\hline Pack-years & $33.4(15.4)$ & $36.1(15.1)$ & $36.4(17.5)$ & $35.2(15.1)$ & $36.1(15.0)$ & $36.1(14.3)$ & $35.5(15.4)$ \\
\hline Ex-smoker & $91(47.9)$ & $85(47.5)$ & $97(51.6)$ & 77 (39.9) & $82(43.9)$ & $100(51.8)$ & $532(47.1)$ \\
\hline Current smoker & $99(52.1)$ & $94(52.5)$ & $91(48.4)$ & $116(60.1)$ & $105(56.1)$ & $93(48.2)$ & $598(52.9)$ \\
\hline $\mathrm{FEV}_{1}(\% \text { predicted })^{\mathrm{b}}$ & $48.7(10.4)$ & $48.6(11.2)$ & $47.1(10.3)$ & $47.9(10.3)$ & $48.0(10.6)$ & $48.1(11.0)$ & $48.1(10.6)$ \\
\hline $\mathrm{FEV}_{1} / \mathrm{FVC}$ ratio $^{\mathrm{b}}$ & $0.454(0.114)$ & $0.445(0.109)$ & $0.452(0.110)$ & $0.445(0.098)$ & $0.431(0.100)$ & $0.439(0.095)$ & $0.444(0.104)$ \\
\hline CAT total score & $20.7(5.1)$ & $20.6(5.5)$ & $21.0(4.9)$ & $20.4(5.0)$ & $20.4(5.1)$ & $20.2(5.0)$ & $20.5(5.1)$ \\
\hline mMRC score & $2.4(0.5)$ & $2.4(0.5)$ & $2.4(0.5)$ & $2.3(0.5)$ & $2.3(0.5)$ & $2.3(0.5)$ & $2.3(0.5)$ \\
\hline
\end{tabular}

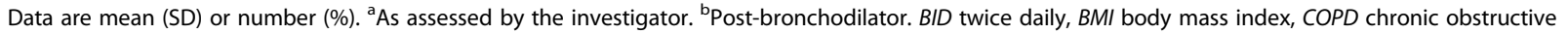
pulmonary disease, FEV forced expiratory volume in $1 \mathrm{~s}, F V C$ forced vital capacity, CAT COPD Assessment Test, mMRC modified Medical Research Council dyspnoea scale

\section{Safety}

All treatments were similarly well tolerated, with no CHF6001 dose-effect, few AEs considered related to treatment, and most AEs being mild or moderate in severity (Table 3 ). The only severe or serious $A E$ to occur in more than one patient in any group was COPD exacerbation (Additional file 1: Supplementary Table 2). No severe or serious AEs were considered related to treatment. Eight patients withdrew due to AEs that were considered treatment related (one or two patients in each active treatment group and three with placebo) the AEs that led to withdrawal from the CHF6001 groups were all mild or moderate in severity. None of the deaths that occurred during the study were considered treatment related: CHF6001 $400 \mu$ g, one patient with two AEs (COPD exacerbation and pneumonia); $800 \mu \mathrm{g}:$ one patient (AE reported only as 'death'); $1200 \mu \mathrm{g}$ : one patient (cardiac arrest); $1600 \mu \mathrm{g}$ : two patients, one with two AEs (coronary artery disease and
COPD exacerbation), and one with AE reported only as 'death'. The incidence of pneumonia AEs was low and similar in all groups, with no treatment-related events. The incidence of AEs of special interest (which included diarrhoea and weight loss) was low, and similar in all groups (see Additional file 1: Supplementary Table 2).

There were no treatment-related trends in biochemistry, haematology, urinalysis or blood pressure data. Mean changes from baseline in heart rate were small and clinically insignificant, as were changes in QTcF interval, with no trends in QTcF interval notable values or notable changes. There were no significant mean changes in bodyweight, and no treatment-related changes in bodyweight or appetite.

\section{Discussion}

CHF6001 had no effect on the primary endpoint measurement of $\mathrm{FEV}_{1}$ at 12 weeks. All four CHF6001 doses demonstrated a similar good overall safety and 


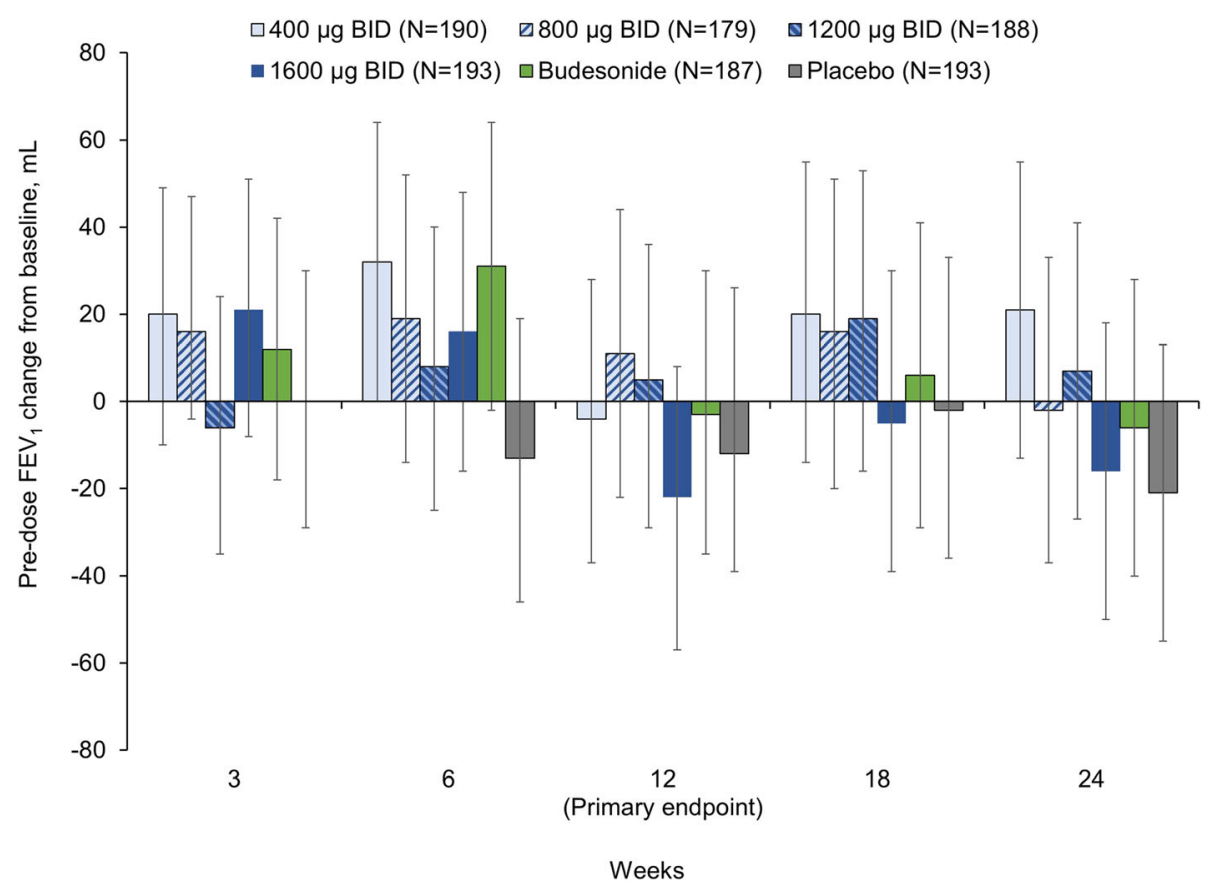

Fig. 2 Adjusted mean pre-dose FEV 1 change from baseline (ITT population). Data are adjusted mean and 95\% confidence intervals. FEV ${ }_{1}$, forced expiratory volume in $1 \mathrm{~s}$; ITT, intention-to-treat; BID, twice daily

tolerability profile. CHF6001 did not have a significant effect on moderate-to-severe exacerbations in the overall population. However, the relative effect of CHF6001 versus placebo on exacerbations was numerically larger in the hypothesis-generating post-hoc analysis of patients with a chronic bronchitis phenotype than in the overall population (although still not significant), and was larger still in the subgroup with both a chronic bronchitis phenotype and baseline blood eosinophil count $\geq 150$ cells $/ \mu \mathrm{L}$, reaching statistical significance for the 800 and $1600 \mu \mathrm{g}$ BID doses.

The good tolerability profile of CHF6001 (including for gastrointestinal adverse events) is notable since treatment with roflumilast, the oral PDE4 inhibitor, is associated with marked gastrointestinal adverse events that has been reported to materially impact patient tolerability [1, 3-7, 13]. Indeed, CHF6001 has been specifically designed to minimise systemic exposure, with inhaled dosing clearly more directly targeting the lungs. Although five patients receiving CHF6001 had AEs that resulted in death, none of these AEs was considered related to treatment by the investigators.

The greater effect of CHF6001 in a defined COPD subgroup is similar to that observed with roflumilast. In an initial one-year study conducted in a broad COPD population, roflumilast improved lung function versus placebo by $39 \mathrm{~mL}$ at 52 weeks $(p=0.001)$ but there was no effect on exacerbations [14]. However, in a subsequent post-hoc analysis pooling data from this study and a second 12-month study, the greatest effect of roflumilast on exacerbations was in the subset of patients with chronic bronchitis (with or without emphysema), in whom there was a $26 \%$ rate reduction versus placebo $(p=0.001)$ [15]. This finding led to the execution of studies that specifically recruited patients with chronic bronchitis, in which roflumilast reduced the exacerbation rate versus placebo by $17 \%(p=0.0003)$ [13]. Furthermore, in patients with chronic bronchitis, the benefit of roflumilast increased with increasing baseline blood eosinophil count [16], and administration of roflumilast significantly reduced eosinophil cell counts in bronchial biopsy samples and induced sputum, suggesting that the efficacy of roflumilast could be due at least in part to an impact on lung eosinophils [17].

The lack of effect in the current study on the lung function endpoints of any of the active treatments (including the ICS positive control) was surprising. This was perhaps partly due to the high variability in these endpoints (as indicated by the wide confidence intervals), with greater variability than seen previously with other PDE4 inhibitors [18, 19]. In addition, there were no consistent treatment-placebo or CHF6001-budesonide differences in any of the symptoms-related endpoints, although there were marked improvements from baseline for these endpoints in all groups including placebo, with mean changes from baseline being close to, 


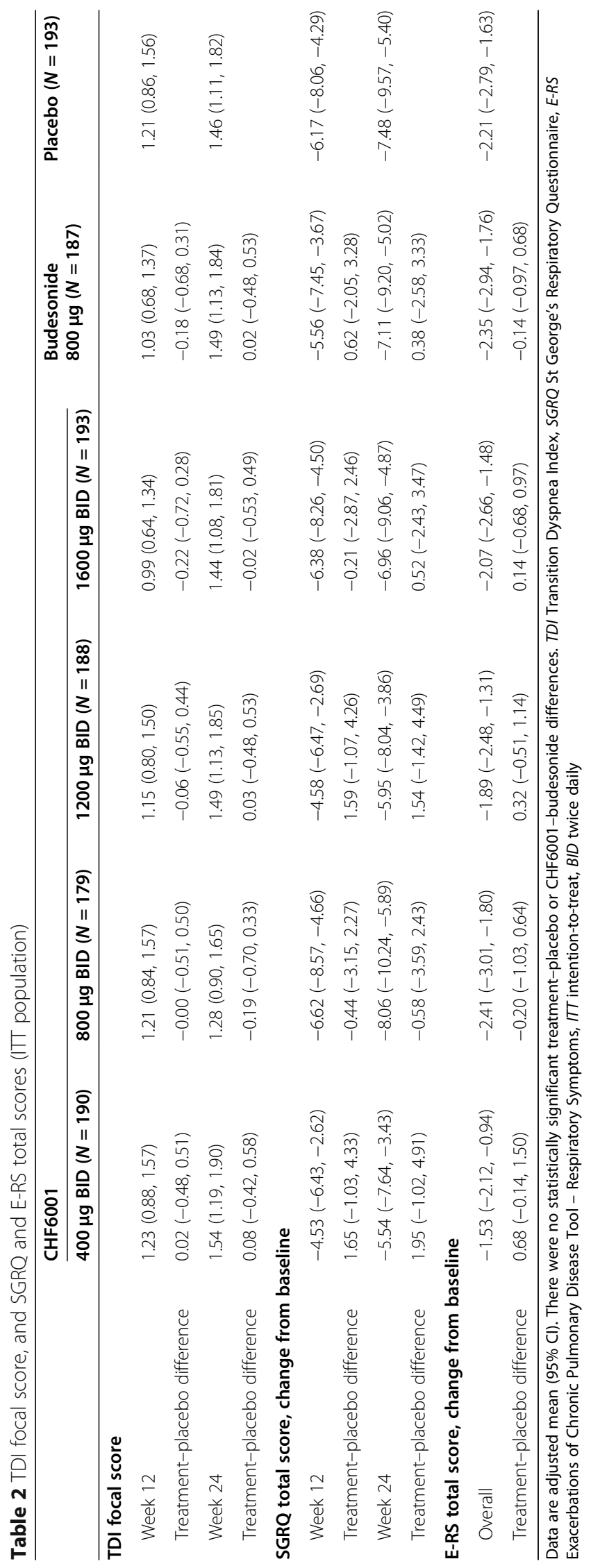




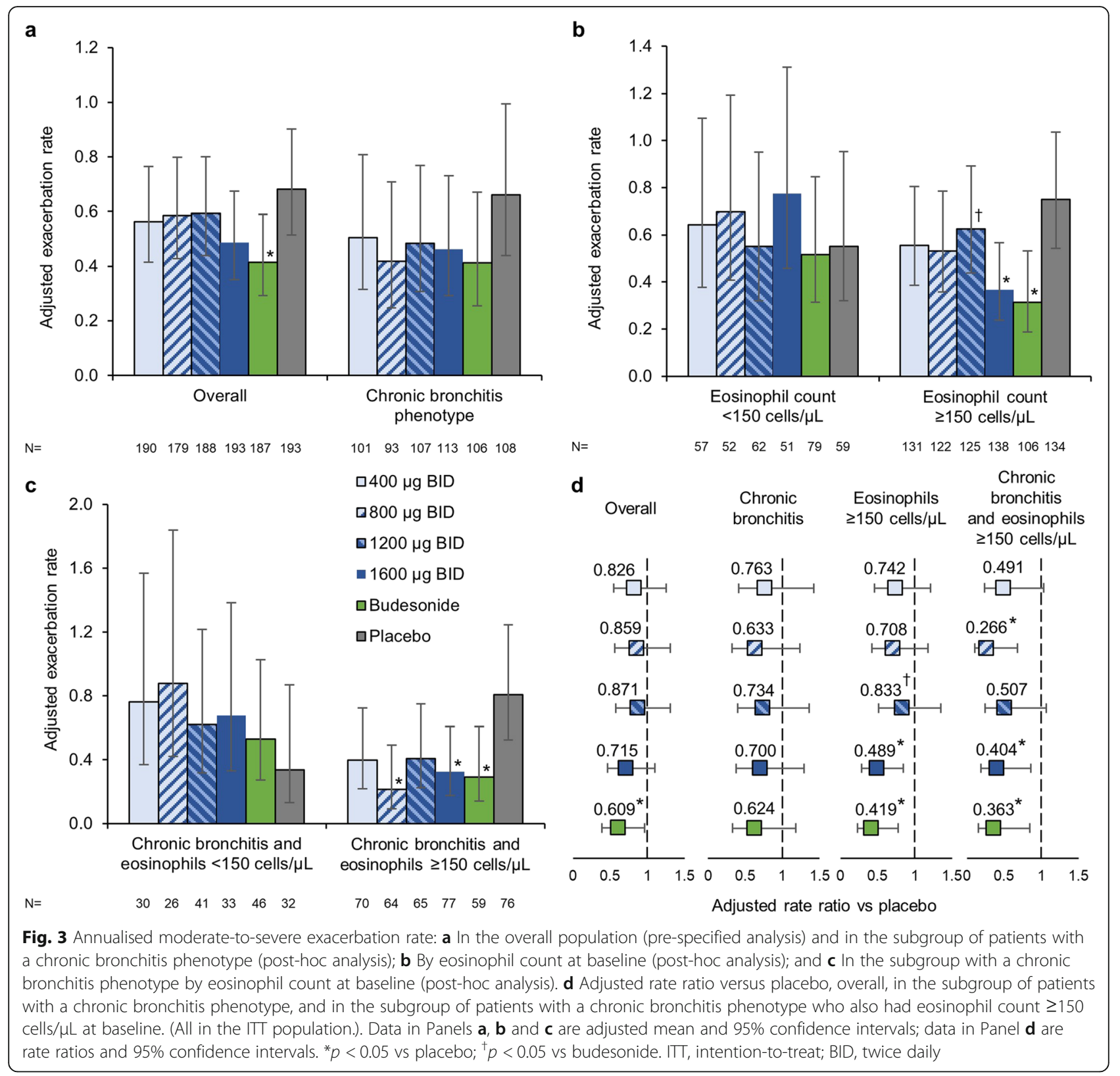

or exceeding clinical relevance for TDI (1 unit), SGRQ (4 units) and E-RS (2 units) at later timepoints. It is important to note that the placebo group received formoterol, which was also administered during the run-in period, and so minimal or no changes were expected during the treatment period in this group. Furthermore, all patients were receiving a LABA plus an ICS before the study, with the ICS withdrawn at the start of the run-in period. Overall, this suggests that a 'trial effect' influenced these endpoints, as such improvements in symptoms with placebo could not be due to treatment itself. A number of studies of other PDE4 inhibitors in patients with COPD have also shown improvements from baseline in symptoms in the placebo arm (although generally modest), but were still able to show differences between active and placebo treatments [3, 13]. Previous studies have also shown a benefit of budesonide plus formoterol compared with formoterol alone on symptoms [20-23]. These contrasting results make the antiinflammatory effect of CHF6001 and budesonide on these endpoints challenging to interpret.

In terms of the biomarkers, SP-D levels were decreased with all four CHF6001 doses but not budesonide, suggesting that this is a PDE4 inhibitor effect and not an ICS effect. SP-D is a secretory product of nonciliated bronchiolar cells [24], circulating levels of which are a biomarker of lung injury, suggesting an active involvement in surfactant metabolism and/or host defence 


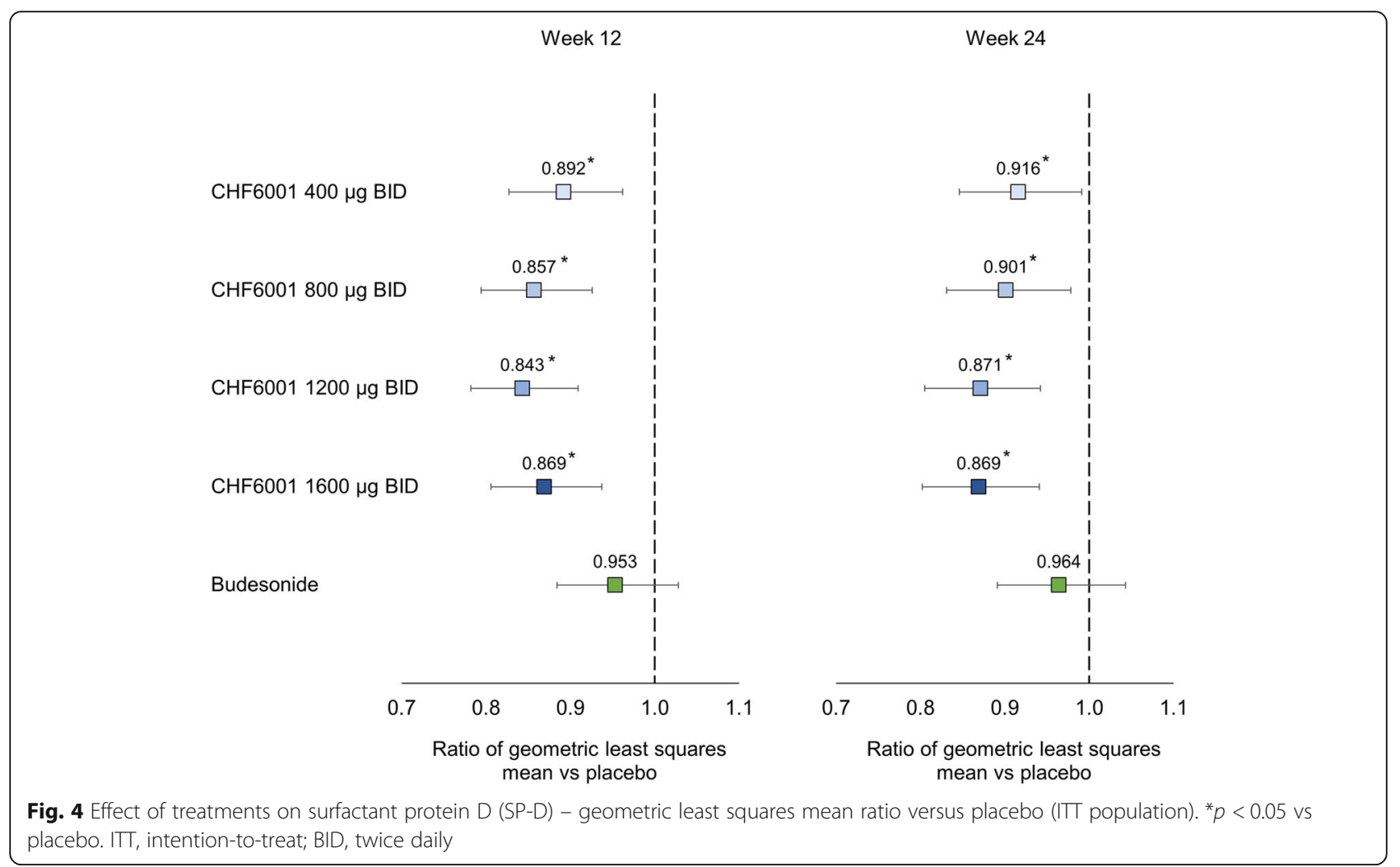

within small airways. This is particularly important in view of the extrafine formulation of CHF6001, which might have the potential to decrease SP-D leakage from the small airways to the systemic circulation and improve small airways integrity. Furthermore, in patients with COPD decreases in circulating SP-D are associated with improvements in health status $[25,26]$. A reduction in SP-D levels was also observed in a previous study in which CHF6001 was administered on top of inhaled triple therapy in patients with a chronic bronchitis phenotype [10]. It is possible that the impact of CHF6001 on SP-D indicates a relevant pharmacological effect that is associated with prevention of COPD deterioration, although this needs to be confirmed in larger, longer studies.

The main limitation was that this study was designed (and powered) to support selection of the optimal CHF6001 dose in terms of effect on lung function, including a 24-week treatment duration. The primary objective was not achieved, and so care needs to be taken over the interpretation of the other data. In addition, the most interesting data are from post-hoc analyses of moderate-to-severe exacerbations, and so by their nature are exploratory, being unpowered and with no

Table 3 Overall adverse events and drug-related adverse events (safety population)

\begin{tabular}{|c|c|c|c|c|c|c|}
\hline & \multicolumn{4}{|l|}{ CHF6001 } & \multirow{2}{*}{$\begin{array}{l}\text { Budesonide } \\
800 \mu \mathrm{g} \\
(N=187)\end{array}$} & \multirow{2}{*}{$\begin{array}{l}\text { Placebo } \\
(N=193)\end{array}$} \\
\hline & $\begin{array}{l}400 \mu \mathrm{g} \text { BID } \\
(N=190)\end{array}$ & $\begin{array}{l}800 \mu \mathrm{g} B I D \\
(N=179)\end{array}$ & $\begin{array}{l}1200 \mu \mathrm{g} \text { BID } \\
(N=188)\end{array}$ & $\begin{array}{l}1600 \mu \mathrm{g} \text { BID } \\
(N=193)\end{array}$ & & \\
\hline Adverse events & $91(47.9)$ & $96(53.6)$ & $94(50.0)$ & $84(43.5)$ & $94(50.3)$ & $103(53.4)$ \\
\hline Drug-related adverse events & $10(5.3)$ & $3(1.7)$ & $6(3.2)$ & $6(3.1)$ & $8(4.3)$ & $14(7.3)$ \\
\hline Severe adverse events & $8(4.2)$ & $10(5.6)$ & $7(3.7)$ & $4(2.1)$ & $6(3.2)$ & $5(2.6)$ \\
\hline Serious adverse events & $11(5.8)$ & $13(7.3)$ & $12(6.4)$ & $7(3.6)$ & $10(5.3)$ & $7(3.6)$ \\
\hline Serious drug-related adverse events & 0 & 0 & 0 & 0 & 0 & 0 \\
\hline Adverse events leading to study drug discontinuation & $5(2.6)$ & $3(1.7)$ & $4(2.1)$ & $8(4.1)$ & $2(1.1)$ & $5(2.6)$ \\
\hline Adverse events leading to death & $1(0.5)$ & $1(0.6)$ & $1(0.5)$ & $2(1.0)$ & 0 & 0 \\
\hline
\end{tabular}


correction for multiplicity; a suitably designed prospective study is needed to confirm these data. Of note, even though eligible patients were required to have a history of at least one exacerbation in the previous 12 months, the rates of these events during the follow-up period was relatively low.

\section{Conclusions}

In conclusion, in this study CHF6001 was well tolerated with a good overall safety profile, but had no effect in the primary lung function analysis and the optimal dose was not identified. However, the post-hoc analyses indicate specific subgroups of patients who may receive particular benefit from CHF6001. Future studies of PDE4 inhibitors should be targeted at these subgroups.

\section{Supplementary information}

Supplementary information accompanies this paper at https://doi.org/10. 1186/s12931-020-01512-y.

Additional file 1. Supplementary methods and results. Methods and results supporting main body of the manuscript.

\section{Acknowledgements}

The authors would like to thank the investigators and patients at the investigative sites for their support of this study.

Dave Singh is supported by the National Institute for Health Research (NIHR) Manchester Biomedical Research Centre (BRC).

\section{Authors' contributions}

The study was conceived by DSi, AE, CF, DSa, MG and MAN. DSi contributed to data acquisition. DSa oversaw the data analyses. All authors interpreted the data, and revised the manuscript for intellectual content and approved the submitted version.

\section{Funding}

This study was funded by Chiesi Farmaceutici SpA.

Writing support was provided by David Young of Young Medical Communications and Consulting Ltd. This support was funded by Chiesi Farmaceutici SpA.

\section{Availability of data and materials}

Chiesi commits to sharing with qualified scientific and medical Researchers, conducting legitimate research, patient-level data, study-level data, the clinical protocol and the full clinical study report of Chiesi Farmaceutici S.p.A.sponsored interventional clinical trials in patients for medicines and indications approved by the European Medicines Agency and/or the US Food and Drug Administration after 1st January 2015, following the approval of any received research proposal and the signature of a Data Sharing Agreement. Chiesi provides access to clinical trial information consistently with the principle of safeguarding commercially confidential information and patient privacy. To date, the current study is out of scope of the Chiesi policy on Clinical Data Sharing.

Other information on Chiesi's data sharing commitment, access and research request's approval process are available in the Clinical Trial Transparency section of http://www.chiesi.com/en/research-and-development/.

\section{Ethics approval and consent to participate}

The study was approved by the independent ethics committees or research boards at each institution. All patients provided written informed consent prior to any study-related procedure.

\section{Consent for publication}

Not applicable.

\section{Competing interests}

DSi received personal fees from Chiesi during the conduct of this study. Outside the submitted work, he reports grants and personal fees from AstraZeneca, Boehringer Ingelheim, Chiesi, GlaxoSmithKline, Glenmark, Menarini, Mundipharma, Novartis, Pfizer, Pulmatrix, Theravance, and Verona, and personal fees from Cipla, Genentech and Peptinnovate.

$A E, M A N, C F, D S a$ and MG are employees of Chiesi, the sponsor of the study.

\section{Author details}

${ }^{1}$ Medicines Evaluation Unit, The University of Manchester, Manchester University NHS Foundation Trust, Manchester, UK. ${ }^{2}$ Global Clinical

Development, Chiesi, Parma, Italy.

Received: 11 April 2020 Accepted: 16 September 2020

Published online: 22 September 2020

\section{References}

1. Global Initiative for Chronic Obstructive Lung Disease. Global strategy for the diagnosis, management, and prevention of chronic obstructive pulmonary disease [Internet]. 2020 [cited 2020 Jul 16]. Available from: https://goldcopd.org/gold-reports/.

2. Vestbo J, Anderson JA, Calverley PMA, Celli BR, Ferguson GT, Jenkins CR, et al. Adherence to inhaled therapy, mortality and hospital admission in COPD. Thorax. 2009;64:939-43. https://doi.org/10.1136/thx.2009.113662.

3. Fabbri LM, Calverley PMA, Izquierdo-Alonso JL, Bundschuh DS, Brose M, Martinez FJ, et al. Roflumilast in moderate-to-severe chronic obstructive pulmonary disease treated with longacting bronchodilators: two randomised clinical trials. Lancet. 2009;374:695-703. https://doi.org/10.1016/ S0140-6736(09)61252-6.

4. Martinez FJ, Rabe KF, Sethi S, Pizzichini E, Mclvor A, Anzueto A, et al. Effect of roflumilast and inhaled corticosteroid/long-acting $\beta 2$-agonist on chronic obstructive pulmonary disease exacerbations (RE2SPOND). A randomized clinical trial. Am. J. Respir. Crit. Care Med. 2016;194:559-67. https://doi.org/ 10.1164/rccm.201607-13490C.

5. Gómez-Rodríguez M, Golpe R. Intolerance to roflumilast in real-life clinical practice. Eur J Intern Med. 2017;43:e28-9. https://doi.org/10.1016/j.ejim.2017. 04.019.

6. Muñoz-Esquerre M, Diez-Ferrer M, Montón C, Pomares X, López-Sánchez M, Huertas D, et al. Roflumilast added to triple therapy in patients with severe COPD: a real life study. Pulm Pharmacol Ther. 2015;30:16-21. https://doi.org/ 10.1016/.jpupt.2014.10.002.

7. Salvesen $\varnothing \mathrm{NU}$, Davidsen JR, Pottegård A, Henriksen DP. Roflumilast usage from 2010 to 2016: a Danish nationwide drug utilization study. Basic Clin Pharmacol Toxicol. 2018;123:314-9. https://doi.org/10.1111/bcpt.13014.

8. Villetti G, Carnini C, Battipaglia L, Preynat L, Bolzoni PT, Bassani F, et al. CHF6001 II: a novel phosphodiesterase 4 inhibitor, suitable for topical pulmonary administration - in vivo preclinical pharmacology profile defines a potent anti-inflammatory compound with a wide therapeutic window. J Pharmacol Exp Ther. 2015;352:568-78. https://doi.org/10.1124/jpet.114. 220558

9. Moretto N, Caruso P, Bosco R, Marchini G, Pastore F, Armani E, et al. CHF6001 I: a novel highly potent and selective phosphodiesterase 4 inhibitor with robust anti-inflammatory activity and suitable for topical pulmonary administration. J Pharmacol Exp Ther. 2015;352:559-67. https:// doi.org/10.1124/jpet.114.220541.

10. Singh D, Beeh KM, Colgan B, Kornmann O, Leaker B, Watz H, et al. Effect of the inhaled PDE4 inhibitor CHF6001 on biomarkers of inflammation in COPD. Respir Res. 2019;20:180. https://doi.org/10.1186/s12931-019-1142-7.

11. Govoni M, Bassi M, Vezzoli S, Lucci G, Emirova A, Nandeuil MA, et al. Sputum and blood transcriptomics characterisation of the inhaled PDE4 inhibitor CHF6001 on top of triple therapy in patients with chronic bronchitis. Respir Res. 2020;21:72.

12. Dupont WD, Plummer WD Jr. Power and sample size calculations for studies involving linear regression. Control Clin Trials. 1998;19:589-601. https://doi.org/10.1016/s0197-2456(98)00037-3.

13. Calverley PMA, Rabe KF, Goehring U-M, Kristiansen S, Fabbri LM, Martinez FJ, et al. Roflumilast in symptomatic chronic obstructive pulmonary disease: two randomised clinical trials. Lancet. 2009;374:685-94. https://doi.org/10. 1016/S0140-6736(09)61255-1.

14. Calverley PMA, Sanchez-Toril F, Mclvor A, Teichmann P, Bredenbroeker D, Fabbri LM. Effect of 1-year treatment with roflumilast in severe chronic 
obstructive pulmonary disease. Am J Respir Crit Care Med. 2007;176:154-61. https://doi.org/10.1164/rccm.200610-15630C.

15. Rennard SI, Calverley PMA, Goehring UM, Bredenbröker D, Martinez FJ. Reduction of exacerbations by the PDE4 inhibitor roflumilast - the importance of defining different subsets of patients with COPD. Respir Res. 2011;12:18. https://doi.org/10.1186/1465-9921-12-18.

16. Martinez FJ, Rabe KF, Calverley PMA, Fabbri LM, Sethi S, Pizzichini E, et al. Determinants of response to roflumilast in severe COPD: pooled analysis of two randomized trials. Am J Respir Crit Care Med. 2018;198:1268-78. https:// doi.org/10.1164/rccm.201712-24930C.

17. Rabe KF, Watz H, Baraldo S, Pedersen F, Biondini D, Baqul N, et al. Antiinflammatory effects of roflumilast in chronic obstructive pulmonary disease (ROBERT): a 16-week, randomised, placebo-controlled trial. Lancet Respir Med. 2018;6:827-36. https://doi.org/10.1016/\$2213-2600(18)30331-X.

18. Rabe KF, Bateman ED, O'Donnell D, Witte S, Bredenbröker D, Bethke TD. Roflumilast--an oral anti-inflammatory treatment for chronic obstructive pulmonary disease: a randomised controlled trial. Lancet. 2005;366:563-71. https://doi.org/10.1016/S0140-6736(05)67100-0.

19. Gamble E, Grootendorst DC, Brightling CE, Troy S, Qiu Y, Zhu J, et al. Antiinflammatory effects of the phosphodiesterase-4 inhibitor cilomilast (Ariflo) in chronic obstructive pulmonary disease. Am J Respir Crit Care Med. 2003;168:976-82. https://doi.org/10.1164/rccm.200212-14900C.

20. Calverley PM, Boonsawat W, Cseke Z, Zhong N, Peterson S, Olsson H. Maintenance therapy with budesonide and formoterol in chronic obstructive pulmonary disease. Eur Respir J. 2003;22:912-9.

21. Rennard SI, Tashkin DP, McElhattan J, Goldman M, Ramachandran S, Martin $\mathrm{UJ}$, et al. Efficacy and tolerability of budesonide/formoterol in one hydrofluoroalkane pressurized metered-dose inhaler in patients with chronic obstructive pulmonary disease: results from a 1-year randomized controlled clinical trial. Drugs. 2009;69:549-65.

22. Tashkin DP, Rennard SI, Martin P, Ramachandran S, Martin UJ, Silkoff PE, et al. Efficacy and safety of budesonide and formoterol in one pressurized metered-dose inhaler in patients with moderate to very severe chronic obstructive pulmonary disease: results of a 6 -month randomized clinical trial. Drugs. 2008;68:1975-2000.

23. Ferguson GT, Tashkin DP, Skärby T, Jorup C, Sandin K, Greenwood M, et al. Effect of budesonide/formoterol pressurized metered-dose inhaler on exacerbations versus formoterol in chronic obstructive pulmonary disease: the 6-month, randomized RISE (revealing the impact of Symbicort in reducing exacerbations in COPD) study. Respir Med. 2017;132:31-41. https:// doi.org/10.1016/j.rmed.2017.09.002.

24. Crouch E, Parghi D, Kuan SF, Persson A. Surfactant protein D: subcellular localization in nonciliated bronchiolar epithelial cells. Am J Physiol Cell Mol Physiol. 1992;263:L60-6. https://doi.org/10.1152/ajplung.1992.263.1.L60.

25. Sin DD, Leung R, Gan WQ, Man SP. Circulating surfactant protein D as a potential lung-specific biomarker of health outcomes in COPD: a pilot study. BMC Pulm Med. 2007;7:13. https://doi.org/10.1186/1471-2466-7-13.

26. Sin DD, Man SFP, Marciniuk DD, Ford G, FitzGerald M, Wong E, et al. The effects of fluticasone with or without salmeterol on systemic biomarkers of inflammation in chronic obstructive pulmonary disease. Am J Respir Crit Care Med. 2008;177:1207-14. https://doi.org/10.1164/rccm.200709-13560C.

\section{Publisher's Note}

Springer Nature remains neutral with regard to jurisdictional claims in published maps and institutional affiliations.

\section{Ready to submit your research? Choose BMC and benefit from:}

- fast, convenient online submission

- thorough peer review by experienced researchers in your field

- rapid publication on acceptance

- support for research data, including large and complex data types

- gold Open Access which fosters wider collaboration and increased citations

- maximum visibility for your research: over $100 \mathrm{M}$ website views per year

At BMC, research is always in progress.

Learn more biomedcentral.com/submissions 